Mr Lajoš Tot, dipl. inž. Vojnotehnicki institut VJ,

Beograd
ISPITIVANJA UTICAJA PARA ACETONA NA MEHANIČKE OSOBINE DVOBAZNIH RAKETNIH GORIVA

UDC: $621.45 .07-6: 547.284 .3-134$

\title{
Rezime:
}

Ova istraživanja obuhvatila su eksperimentalno $i$ teorijsko izučavanje uticaja delovanja para acetona na mehaničke osobine dvobaznih raketnih goriva. Istraživanja su izvedena na dva definisana dvobazna raketna goriva. Prikazani su rezultati mehaničkih ispitivanja netretiranih $i$ tretiranih dvobaznih raketnih goriva $i$ nastojano je da se objasni uočeni fenomen.

Ključne reči: mehaničke osobine, dvobazno raketno gorivo.

\section{INVESTIGATION OF THE ACETONE VAPOUR INFLUENCE ON THE MECHANICAL PROPERTIES OF DOUBLE BASE PROPELLANTS}

\section{Summary:}

These investigations included experimental and theoretical study of acetone vapours influence on the propellant mechanical properties. The tests were carried out on two defined propellants. Herein shown are the results of the mechanical tests of both non-treated and treated propellants as well as an attempt to explain the observed phenomenon.

Key words: mechanical properties, double base propellant.

\section{Uvod}

Dvobazna raketna goriva (DRG) jesu materije koje u procesu sagorevanja, u relativno kratkom vremenu, oslobadaju veliku kolicinu gasovitih produkata. Ovako nastali gasoviti produkti sagorevanja pokreću raketu. Da bi se ona kretala zahtevanom putanjom, pogonskom punjenju (od DRG) mora se dati tačno određeni geometrijski oblik, tj. omoguciti kontrolisani dotok produkata sagorevanja. $\mathrm{Za}$ vreme trajanja procesa sagoreva- nja pogonsko punjenje izloženo je mehanickim naprezanjima usled ubrzanja rakete, rotacije oko uzdužne ose (centrifugalne sile), razlike pritisaka u motoru (erozije baruta) i dr. Ukoliko u toku leta rakete dođe do loma pogonskog punjenja, tada dolazi do nekontrolisane promene u kolicini nastalih gasovitih produkata sagorevanja, što ima za posledicu nekontrolisanu promenu u parametrima putanje rakete, a može dovesti $i$ do njenog razaranja. Odavde se vidi važnost kvantitativnog i kvalitativnog poznavanja meha- 
nickih naprezanja kojima je izloženo pogonsko punjenje (određenog geometrijskog oblika) u datom raketnom motoru, radi izbora DRG odgovarajućih mehanickih osobina [1].

U praksi se može javiti slučaj da DRG zadovoljavajućih kinetickih osobina mora imati bolje mehanicke osobine od postojećih. To može biti slučaj npr. kod impulsnih raketnih motora, gde odgovarajuće kinetičke osobine poseduju jedan do dva barutna sastava, ali imaju niže vrednosti mehanickih osobina od zahtevanih. Ukoliko bi promenom u sastavu (npr. povećanjem masenog udela nitroceluloze) dobili porast $\mathrm{u}$ mehanickim osobinama, tada bi izgubili zahtevane kineticke ili toplotne osobine. U ovom radu učinjen je pokušaj da se poboljకaju mehanicke osobine na nekoliko DRG, koji nalaze ili bi mogli naći primenu u impulsnim raketnim motorima, ne menjajući sastav DRG, tj. ne menjajući znacajnije njihove kinetickke osobine.

Osnovu za pokušaje iznalaženja poboljsanja mehaničkih osobina predstavljala su zapažanja da se pod dejstvom para organskih rastvarača (npr. acetona) bitno menjaju mehaničke osobine DRG, tako da su uočeni fenomeni pobudili interes i za detaljnija proucavanja.

Dvobazna raketna goriva, koja su razmatrana, proizvedena su postupkom ekstruzije (presovanja), čiji je postupak proizvodnje odavno poznat [2,3].

Pored nitroceluloze (NC), nitroglicerina i hemijskog stabilizatora kao osnovnih komponenti, koje su sastavni deo svakog DRG, barutna masa sadrži i plastifikatore, balisticke i tehnološke aditive.

\section{Želatinizacija nitroceluloze}

Želatinizacija NC je od fundamentalnog značaja za njenu primenu koja je ogromna [4]. Nitroceluloza se dobija esterifikacijom celuloze, što je karakteristican primer topohemijske reakcije [4], tj. reakcije čvrste faze u tečnoj sredini, bez razlaganja, čak i bez izmene strukture te črrste faze.

Prostorni izgled NC razlikuje se od prostornog izgleda celuloze. Razlog je uvođenje voluminoznih $\mathrm{NO}_{2}$ grupa, koje mogu zauzimati razne položaje, jer postoji mogućnost slobodne rotacije oko veza C-O i O- $\mathrm{NO}_{2}$.

Nitroceluloza i dalje zadržava vlaknastu strukturu, ali je stereoregularnost mnogo manja nego kod celuloze, posebno zbog mogućih razlicitih prostornih položaja bočnih nizova (O-NO [5]. Dakle, sa porastom razgranatosti (porastom broja $\mathrm{O}-\mathrm{NO}_{2}$ grupa), tj. porastom procenta azota smanjuje se udeo kristalienosti, odnosno dolazi do razmicanja lanaca NC. Time se i objašnjava razlicita rastvorljivost $\mathrm{NC}$ u funkciji stepena nitracije.

U svojoj strukturi NC sadrži zone u kojima je kristalična i zone u kojima je amorfna. Pristupačnost ovih zona delovanju agensa je razlicita, što se u velikoj meri odražava na proces želatinizacije. Kada je NC suva ona je opasan eksploziv, osetljiv na udar i trenje. Njena primena je rešena tek kada je njen oblik sitnih pahuljica transformisan u želatinisanu, pravu plastičnu masu, cije je sagorevanje relativno sporo i kontrolisano po paralelnim slojevima [4].

$\mathrm{Da}$ bi se izvršila želatinizacija NC mora postojati afinitet izmedu $\mathrm{NC}$ i mo- 
lekula sposobnih da se „vežu“, ne razarajući u potpunosti strukturu NC. Ostvareni gel mora biti hemijski stabilan i otporan na povratne procese migracije želatinizatora na površinu.

Postoji više postupaka želatinizacije NC. Spomenucemo dva $\mathrm{i}$ to pomoću „rastvarača" ketonskog tipa i teško isparljivih plastifikatora tipa „nitroestara“. Pri želatinizaciji rastvaračem ketonskog tipa po obavljenoj želatinizaciji rastvarač se odstranjuje iz NC. To su rastvaraci koji nakon obavljene funkcije želatinizacije bivaju eliminisani iz NC. Tu spadaju: aceton (najaktivniji i rastvara sve tipove NC), etilacetat (takode je pravi rastvarac NC), butilacetat i smeša etiletar-etanol (65:35) koja rastvara NC sadržajem azota od 10,5 mas $\%$ do 12,8 mas\%. Ovde spadaju i neisparljive materije koje ostaju u barutu: estri ftalne kiseline (dietilftalat i dibutilftalat), triacetin, pojedini nitrili, centralit I i drugi.

Jedno od mogućih objašnjenja delovanja acetona na NC jeste da je pri vezivanju acetona na nitrocelulozu ona kiselog karaktera, a aceton baznog. Svi elektroni u vezama gde je došlo do esterifika-

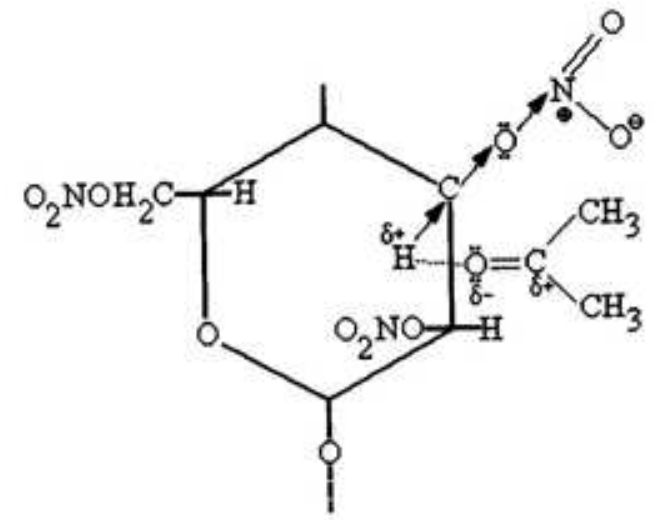

SI. I - Delovanje selatinizatora ketonskog tipa na nitrocelulozu cije pomereni su ka azotu (slika 1) zbog negativnog indikacionog efekta nitro grupa. Zbog toga je vodonikov atom vezan za ugljenik sa izraženim kiselim karakterom, tako da je u stanju da za sebe veže atom sa slobodnim elektronskim parom ( $\mathrm{tj}$. za kiseonikov atom $\mathrm{u}$ acetonu). Svaki vodonikov atom vezan za sekundarne ugljenikove atome ima više izražen kiseli karakter, od vodonikovih atoma vezanih za primarne ugljenikove atome, s obzirom na to da je pomeranje elektrona rasporedeno na jedan vodonikov atom [1]. S druge strane, aceton ima bazni karakter. Elektroni su pomereni ka elektronegativnom kiseoniku, zbog cega kiseonik ima mali negativni naboj $(\delta-)$, a ugljenik mali pozitivni naboj $(\delta+)$.

S obzirom na kiselo svojstvo vodonikovog atoma iz $\mathrm{NC}$ i na bazno svojstvo kiseonika iz acetona, lako se uspostavlja vodonicna veza. Ako u NC ima slobodnih hidroksilnih grupa takode bi se mogla uspostaviti vodonicna veza sa acetonom.

$\mathrm{U}$ radu [6] ustanovljeno je da neisparljivi želatinizatori ketonskog tipa (npr. centralit I) grade vodonicne veze sa hidroksilnim grupama NC. Pri želatinizaciji plastifikatorima tipa nitroestara, plastifikator ostaje u konačnom sastavu DRG [4]. U ovu grupu spadaju: nitroglicerin, nitroglikol, dietilenglikoldinitrat, dinitrotoluol i dr. Detaljan prikaz mehanizma želatinizacije dat je u radovima $[1,7]$.

Već je pomenuto da je najaktivniji rastvarac nitroceluloze aceton. Rastvaranje nitroceluloze odvija se u dve faze, pri cemu je prva faza bubrenje, a druga rastvaranje [1].

Pri bubrenju nitroceluloze molekuli rastvaraca mogu difundirati izmedu ma- 
kromolekula NC, pri cemu dolazi do povećanja zapremine i mase NC. Porast mase jednak je masi apsorbovanog rastvaraca. Bubrenje NC je istovremeno i kapilarno i molekularno. Kod kapilarnog bubrenja [1] rastvarač prodire u praznine - kanale, pri čemu se micele razdvajaju.

Kod molekularnog bubrenja [5] rastvarač prodire izmedu makromolekula NC. Nitroceluloza pri neprestanom dotoku rastvarača neogranið̌eno bubri, tj. postepeno gubi svoj oblik i na kraju prelazi u rastvor. Prodiranjem molekula acetona dolazi do povećanja rastojanja između makromolekula NC, što dovodi do smanjenja broja i jačine poprex̌nih sekundarnih veza.

Ukoliko se prekine dotok rastvaraca pre nego što NC izgubi svoj spoljni oblik dolazi do ogranicenog bubrenja NC.

Kada se nabubreloj NC dovodi rastvarač, postepeno dolazi do potpunog raskidanja međumolekulskih veza u $\mathrm{NC}$, (makromolekuli se medusobno potpuno odvoje molekulama rastvaraca) pa dolazi do rastvaranja NC. Kada se iz ovakvog rastvora potpuno odstrani rastvarač, NC će ponovo preći u čvrsto stanje, ali sa drugacijim rasporedom makromolekula. Ovakva NC potpuno gubi vlaknastu trukturu [1].

\section{Rezultati eksperimentalnih ispitivanja}

Hemijski sastavi i fizicko-hemijske osobine opitnih modela DRG1 i DRG2 prikazani su u radu [1]. Sadržaj črstih balistickih aditiva u DRG1 je oko $3 \%$, a u DRG2 oko 4\%. Sadržaj NC u oba sastava je isti i iznosi oko $55,5 \%$. U DRG2 ima oko 3\% NGL manje nego u DRG1, ali ima oko $3 \%$ dietilftalata.
Ispitivanje uticaja delovanja para

acetona na mehaničke osobine DRG

Ova ispitivanja rađena su na sastavima DRG1 i DRG2. Epruvete za ispitivanje zatezne évrstoce isecane su iz barutnog platna, debljine $2 \mathrm{~mm}$, u smeru valjanja [1]. Oblik i dimenzije epruveta prikazane su na slici 2 . Sva ispitivanja mehanickih osobina, ukoliko nije posebno naznačeno, rađena su na normalnoj temperaturi.

Epruvete tipa E1 (slika 2) tretirane su delovanjem para acetona u zatvorenoj posudi [1] na temperaturi od $20^{\circ} \mathrm{C}$ u vremenu 1, 2, 3, 4 i 5 sati (DRG1), odnosno $1,2,3,4,5,6$ i 7 sati (DRG2). Nakon završenog tretiranja, epruvete su na $20^{\circ} \mathrm{C}$ sušene do konstantne mase. Rezultati ispitivanja jednoosnim zatezanjem, pri brzini hoda hvataljki $100 \mathrm{~mm} / \mathrm{min}$, kao srednje vrednosti 5 merenja (DRG1), odnosno 7 merenja (DRG2), prikazani su u tabeli 1 . U tabeli 1 su: $\sigma_{z}$-prekidna zatezna čvrstoća, $\varepsilon$ - prekidna deformacija, $\sigma_{k}$ - kritična zatezna čvrstoća i $\tau$ - vreme tretiranja. Kritična zatezna čvrstoća uzimana

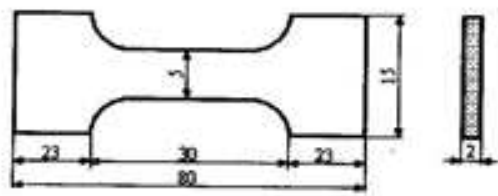

Epruveta E1

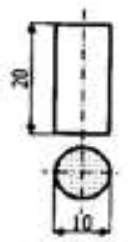

Epruveta E:2

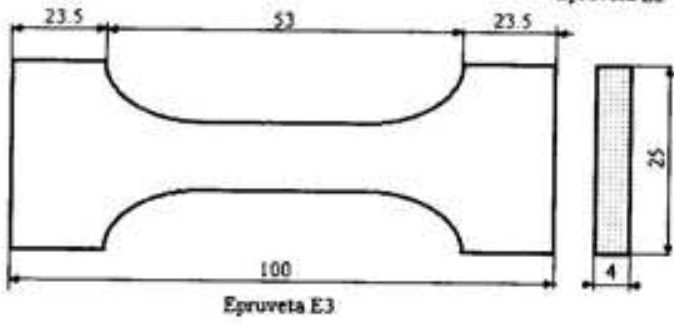

Sl. 2 - Epruvete za ispitivanje mehaničkih osobina 
Mehanicke osobine DRGI i DRG2 sa i bez naknadnog valjanja

\begin{tabular}{|c|c|c|c|c|c|c|}
\hline \multicolumn{2}{|c|}{$\sigma_{z}\left(\mathrm{daN} / \mathrm{cm}^{2}\right)$} & \multicolumn{2}{c|}{$\varepsilon(\%)$} & \multirow{2}{*}{ Primedba } \\
\cline { 1 - 4 } DRG1 & DRG2 & DRG1 & DRG2 & DRG1 & DRG2 & \\
\hline 127,4 & 164,8 & 10,9 & 16,7 & 0 & 0 & bez naknadnog valjanja \\
\hline 115,4 & 160,6 & 10,1 & 16,4 & 0 & 0 & sa naknadnim valjanjem \\
\hline 194,7 & 310,1 & 19,4 & 45,0 & 5 & 3,5 & bez naknadnog valjanja \\
\hline 128,4 & 162,2 & 12,9 & 14,8 & 5 & 3,5 & sa naknadnim valjanjem \\
\hline
\end{tabular}

Uticaj naknadnog termičkog $i$ mehaničkog tretmana DRG na efekte delovanja para acetona

Dobijeni rezultati pokazali su da delovanje para acetona dovodi do znatnog povećanja mehaničkih osobina DRG. Medutim, DRG u obliku barutnih ploca javljaju se u proizvodnji kao medufazni proizvod od kojeg se ekstruzijom oblikuju pogonska punjenja zahtevanih oblika i dimenzija.

S obzirom na to da su DRG termoplastični materijali, ovo oblikovanje se obavlja na povišenoj temperaturi mehaničkim delovanjem na prethodno pripremljene barutne mase. Dakle, naknadni termickki i mehanički tretman može uticati na efekte ostvarene delovanjem para acetona, pa su sprovedena ispitivanja uticaja dalje prerade barutnih ploča na efekte ostvarene delovanjem para acetona. Ova ispitivanja vršena su na barutnim pločama od DRG1 i DRG2, koje su prethodno tretirane 5 , odnosno 3,5 sati parama acetona $\mathrm{i}$ isecane epruvete tipa E1.

Tretirane i osušene barutne ploče propuštane su 18 puta kroz valjke zagrejane na $98^{\circ} \mathrm{C}$. U toku ovog valjanja uzeti su uzorci barutnog platna $\mathrm{i}$ iz njih isecene epruvete tipa E1. Ispitane mehanicke osobine, za DRG1 i DRG2, navedene su u tabeli 2 .
Posle valjanja i formiranja svitka izvršeno je oblikovanje ekstruzijom i dobijena su pogonska punjenja u obliku punog cilindra prečnika $31,5 \mathrm{~mm}$ koja su sečena na dužinu $110 \mathrm{~mm}$. Iz ovih punjenja isecane su epruvete tipa E2 i E3 (slika 2), a dobijene mehanicke osobine navedene su u tabelama 3,4 i 5 .

$\mathrm{U}$ tabelama 3 i $5 \sigma_{p}$ označava maksimalnu čvrstoću na pritisak, $\sigma_{\mathrm{pk}}$ kritičnu ¿vrstoću na pritisak i E modul elastičnosti. On je određivan povlačenjem tangente na pocetni (linearni) deo krive i izračunavanjem nagiba tangente.

Tabela 3

Mehaničke osobine DRGI nakon ekstrudovanja

\begin{tabular}{|c|c|c|c|c|}
\hline $\begin{array}{c}\sigma_{\rho_{1}} \\
\left(\mathrm{daN}_{\mathrm{cm}^{2}}\right)\end{array}$ & $\begin{array}{c}\sigma_{\mathrm{pk}} \\
\left(\mathrm{daN} / \mathrm{cm}^{2}\right)\end{array}$ & $\begin{array}{c}\mathrm{E} \\
\left(\mathrm{daN} / \mathrm{cm}^{2}\right)\end{array}$ & $\begin{array}{c}\tau \\
(\mathbf{h})\end{array}$ & Primedba \\
\hline 306,0 & 96,6 & 2708 & 5 & epruvete tipa E2 \\
\hline 292,2 & 79,8 & 2767 & 0 & epruvete tipa E2 \\
\hline
\end{tabular}

Mehaničke osobine DRG2 nakon ekstrudovanja na $29^{\circ} \mathrm{C}$

\begin{tabular}{|c|c|c|c|}
\hline$\sigma_{z}\left(\mathrm{daN} / \mathrm{cm}^{2}\right)$ & $\varepsilon(\%)$ & $\tau(\mathrm{h})$ & Primedba \\
\hline 153,2 & 19,2 & 0 & epruvete tipa E3 \\
\hline 142,5 & 18,1 & 3,5 & epruvete tipa E3 \\
\hline
\end{tabular}

Tabela 5

Mehaničke osobine DRG2 nakon ekstrudovanja na $50^{\circ} \mathrm{C}$

\begin{tabular}{|c|c|c|c|}
\hline$\sigma_{p}\left(\mathrm{daN} / \mathrm{cm}^{2}\right)$ & $\begin{array}{c}\sigma_{\mathrm{p}^{k}} \\
\left(\mathrm{daN} / \mathrm{cm}^{2}\right)\end{array}$ & $\tau(\mathrm{h})$ & Primedba \\
\hline 141,6 & 18.0 & 3,5 & epruvete tipa E2 \\
\hline 141,5 & 18,8 & 0 & epruvete tipa E2 \\
\hline
\end{tabular}


Rezultati ispitivanja pokazuju da naknadna prerada i tretiranih i netretiranih DRG1 i DRG2, bilo ponovo u barutne ploče (tabela 2 ), bilo u ekstrudovana pogonska punjenja (tabele 3,4 i 5) izaziva značajne promene $u$ mehanickim osobinama tretiranih i male promene kod netretiranih DRG. U svim slucajevima, pri naknadnoj preradi, dobijene vrednosti mehanickih osobina cak su malo ispod odgovarajućih vrednosti netretiranih, odnosno nepreradivanih DRG. Verovatni uzrok ovom padu mehanickih osobina jeste degradacija makromolekula NC usled mehaničkog tretmana.

\section{Analiza rezultata}

Želatinizacija NC nitroglicerinom u procesu izrade DRG obavlja se termičkim i mehanickim tretmanom barutne mase, pri cemu ona dobija željeni geometrijski oblik, a izrađeni DRG definisanu fizičku strukturu. Po završetku izrade DRG, u toku odležavanja, dolazi do izvesne kontrakcije po dužini u smeru primenjene spoljne sile $\mathrm{i}$ do ekspanzije po širini punjenja, dakle, normalno na smer primenjene sile. Ovaj proces naziva se relaksacija naprezanja. Kako se proces relaksacije ne može u potpunosti ostvariti u nekom konačnom vremenu, u DRG zaostaju unutrašnji naponi. Kada se DRG podvrgne delovanju para acetona dolazi do njegovog bubrenja. Naime, molekuli acetona difunduju u DRG, interreaguju sa aktivnim mestima u NC, razmicu susedne makromolekule, odnosno, stvaraju uslove da delovi makromolekula NC zauzimaju energetski stabilnije konformacione položaje i tako, zavisno od vreme- na delovanja para acetona, dolazi do potpunije relaksacije unutrašnjih napona u barutu.

Rezultati sprovedenih ispitivanja potvrdili su ovakva razmatranja. Poboljకanje mehanickkih osobina u odnosu na netretirani DRG, npr. DRG1 (za $\tau=5 \mathrm{~h}$ ), iznosi oko $118 \%$ za zateznu čvrstoću, a za izduženje oko $570 \%$, dok su odgovarajući porasti mehaničkih osobina za DRG2 (za $\tau=7 \mathrm{~h}$ ) oko $150 \%$ za zateznu čvrstoću i za izduženje oko $240 \%$.

Oblici krivih sila - deformacija, koji se dobijaju pri jednoosnom istezanju, razlikuju se od oblika odgovarajućih krivih tretiranih DRG (slika 3). Na pocetnom delu krivih sila - deformacija netretiranih DRG (slika $3, \tau=0$ ), javlja se linearni deo koji odgovara trenutno povratnoj elastičnoj deformaciji (do tačke A). Dalje se javlja krivolinijski deo, koji odgovara visokoelastičnoj deformaciji (oblast AB).

Oblici krivih sila - deformacija, koji se dobijaju pri jednoosnom istezanju tretiranih DRG, razlikuje se od oblika odgovarajucih krivih netretiranih baruta (slika 3 , krive $\tau=1, \tau=2, \tau=3, \tau=4$ i $\tau=5$ ). Sa porastom vremena tretiranja na dijagramima se uocava infleksija. Dakle, na dijagramima sila - deformacija javlja se linearni deo (tacka A na slici 3), koji odgovara trenutno povratnoj elastičnoj deformaciji, zatim krivolinijski deo $\mathrm{AB}$ (konveksan u odnosu na apscisnu osu), koji odgovara visokoelasticnoj deformaciji i na kraju se javlja oblast BC koja odgovara visokoplastičnoj deformaciji. U ovoj oblasti dolazi do izvesne orijentacije delova makromolekula (pri delovanju jednoosnog naprezanja) $[3,8]$. Ova ori- 
jentacija makromolekula (u oblasti CD) izaziva nagli porast sile (tzv. „očvršćavanje"), a što na krivama sila - deformacija odgovara nastajanju drugog linearnog dela krive, počev od tačke D, i u ovoj oblasti dolazi do loma epruvete. Dakle, do loma dolazi pri većim vrednostima sile $\mathrm{i}$ deformacije nego kod netretiranih DRG.

Kada se i tretirani i netretirani DRG podvrgne ponovnoj preradi, dolazi do smanjenja mehanickih osobina u oba slucaja, cak na niži nivo nego što je imao odgovarajući DRG pre ponovne prerade. Moguće objašnjenje je da, pri ponovnom termickom i mehanickom tretmanu DRG, dolazi do izvesne orijentacije delova makromolekula NC, što je praćeno ponovnim stvaranjem unutrašnjih napona, kao i do dodatne degradacije makromolekulskih lanaca.

$\mathrm{U}$ ovom ispitivanju korišćena su barutna platna debljine $2 \mathrm{~mm}$. Tretiranje barutnog platna većih debljina verovatno bi zahtevalo dugotrajnije sušenje da bi se izbegao uticaj zaostalog acetona, što bi moglo biti predmet nekog budućeg rada.

\section{Zaključak}

Rezultat delovanja para acetona na DRG je povećanje stepena želatinizacije NC i potpunija relaksacija unutrasnjih napona u barutu, pa se kao rezultat javlja poboljšavanje mehaničkih osobina DRG. Delovanje para acetona na DRG pokazuje znatan porast kritiěne i prekidne zatezne čvrstoće i prekidnog izduženja. Acetonom tretirana DRG, ukoliko se podvrgavaju naknadnom termičkom i mehanickom tretmanu, pokazuju smanjenje mehanickih osobina čak na niži nivo nego što su imala odgovarajuća netretirana DRG pre ponovne prerade.

Može se zaključiti da acetonom tretirana DRG, ukoliko se ne podvrgavaju naknadnom termičkom i mehanickom tretmanu, treba koristiti za laboraciju u raketne motore. $\mathrm{Na}$ taj način zadržava se postignuti visoki nivo mehanickih osobina.

\section{Literahura:}

[1] Tot, L. Istrazivanje uticaja delovanja para organskih rastvaraca na mehanicke osobine dvobaznih raketnih baruta, Tchnolosko-metalurski fakultet, Beograd, magistarski rad, 1989.

121 Maksimovic, P. V.: Tehnologija eksplozivnih materijala, Vojnotehnicki zavod, Beograd, 1972.

[3] Miles, F. D. Cellulose nitrate, Imperial chemical industries limited, 1955.

14] Petrovic, M.; Hristovski, M.; Macic K.: XII Simpozijum o eksplozivnim materijalima, Knjiga 1, str. 177-213.

[5] Stojanovic, O.; Stojanovic N.: Hemija ugljenih hidrata, Tehnolosko-metalurski fakultet, Beograd 1979.

[6] Brodman, B. W.; Lampner, N.; Devin M. P.: J. Appl. Polym. Sci., 26(5). 1981.

[7] Stojanovic, R.: Uticaj tehnoloških parametara zelatinizacije na mehanicke karakteristike i prijedlog metoda za odredivanje stepena zelatinizacije dvobaznih raketnih goriva, Tehnoloski fakultet, Novi Sad, magistarski rad, 1988.

[8] Gulj, V. E.: Struktura i mehanicke osobine polimera, Moskvva, 1972. 